\title{
Relationship between genetic and environmental factors and hypercholesterolemia in children
}

\author{
Jorge A. Robledo, B.S. ${ }^{a}$, and Leonardo J. Siccardi, B.S. ${ }^{a}$
}

\begin{abstract}
Introduction. Pediatric hypercholesterolemia has increased over the past decades. Knowing the environmental and genetic factors that have an impact on it would allow establishing more adequate screening guidelines.

Objectives. To determine if there is an association between genetic and environmental factors and hypercholesterolemia in children. To assess the predictive qualities of outcome measures associated with hypercholesterolemia.

Material and methods. Observational, analytical, cross-sectional study. Population: students from all schools located in Jovita. Age: $\geq 6$ and $<12$ years old. The total cholesterol level was measured. A survey was administered to parents to assess their family medical history (FMH) and socioeconomic level (SEL). Weight and height were recorded to establish nutritional status. A survey was administered to children to identify their level of physical activity and their eating habits. The association was assessed by estimating the OR value $(p<0.05)$. Diagnostic tests were done to establish outcome measures that predict hypercholesterolemia.

Results. Threehundred and eighty-two students were included. Their mean cholesterol level was $168 \mathrm{mg} / \mathrm{dL}$, and $13.4 \%$ had hypercholesterolemia. A sedentary lifestyle was observed in $22.8 \%$, and obesity, in $10.5 \%$. A positive FMH, a high/ middle SEL, and obesity were associated with hypercholesterolemia (OR: 2.10, 2.10 and 2.05, respectively). No association was found between physical activity and fat/cholesterol intake and hypercholesterolemia. A positive FMH and a high/middle SEL were sensitive enough $(75 \%$ and $88 \%$ ) to predict hypercholesterolemia. The presence of hypercholesterolemia in both parents in relation to hypercholesterolemia in their child showed an OR of 9.59 , a sensitivity of $73 \%$, a specificity of $71 \%$, a positive predictive value of $57 \%$, and a negative predictive value of $83 \%$. Conclusions. A positive FMH, a high/ middle SEL, and obesity were associated with hypercholesterolemia in children. The presence of hypercholesterolemia in both parents was associated with hypercholesterolemia in their child and showed itself to be a great potential predictor and screening criterion.

Key words: hypercholesterolemia, risk factors, children, parents
\end{abstract}

http:/ /dx.doi.org/10.5546/aap.2016.eng.419

\section{INTRODUCTION}

The Horus study demonstrated that atherosclerosis has been present in human beings since at least 2500 B.C. ${ }^{1}$

The prolongation of current life expectancy has resulted in heart disease to be one of the main causes of morbidity and mortality worldwide. In addition, related risk factors have also increased, including hypercholesterolemia, obesity, arterial hypertension, smoking, and a sedentary lifestyle. ${ }^{2}$

Autopsies done in young soldiers killed in the Korean $\mathrm{War}^{3}$ and the Pathobiological Determinants of Atherosclerosis in Youth (PDAY) study ${ }^{4}$ show that atherosclerosis may begin at an early age.

The prevalence and mean values of hypercholesterolemia in children has increased in many countries, ${ }^{5}$ mainly due to changes in eating habits $^{6}$ and the increase in the time spent in sedentary occupational and recreational activities. ${ }^{7}$ An association has been described between hypercholesterolemia and a higher socioeconomic status, ${ }^{8}$ whereas results have been dissimilar in relation to obesity, sometimes even contradictory. ${ }^{9}$

Some experts recommend establishing the cholesterol level as part of a universal screening. ${ }^{10}$ The Argentine Society of Pediatrics (Sociedad Argentina de Pediatría, SAP), ${ }^{11}$ in concordance with the American Academy of Pediatrics, recommends assessing children whose parents and/or grandparents have early vascular disease or whose parents have hypercholesterolemia. This method lacks predictive value. ${ }^{12}$

The goal of this study was to assess 
outcome measures that may be associated with hypercholesterolemia in children and look for new screening criteria.

\section{OBJECTIVES}

To determine if there is an association between genetic and environmental factors and hypercholesterolemia in children.

To assess the predictive qualities of outcome measures associated with hypercholesterolemia.

\section{MATERIAL AND METHODS}

Observational, analytical, cross-sectional study conducted in April-May 2009.

\section{Population}

All students attending primary school $(n=503)$ in the municipality of Jovita, Córdoba (Argentina) during the 2009 school year.

\section{Inclusion criteria}

- Being $\geq 6$ and $<12$ years old by June $30^{\text {th }}, 2009$.

- Having obtained an informed consent signed by the father, mother or legal guardian and the minor's assent, if applicable.

\section{Exclusion criteria}

- Refusing to participate in the blood draw or missing the appointment.

- Having an infectious disease at present or within 20 days before the blood draw. ${ }^{13}$

- Having nephrotic syndrome, hypothyroidism, or diabetes.

\section{METHODOLOGY}

\section{Cholesterol level outcome measure}

Blood drawn from a vein upon fasting for at least 10 hours was used. Total cholesterol (TC) level was measured using the enzymatic AA liquid Colestat method (Wiener Lab). Hypercholesterolemia was defined as equal to or higher than $200 \mathrm{mg} / \mathrm{dL}$. Serum was separated within the first hour following the blood draw, and tests were done in the same day using a Metrolab 2100 autoanalyzer. The technique used to measure cholesterol was subjected to a traceability control through the Reference and Standardization Lab for Clinical Biochemistry (Laboratorio de Referencia y Estandarización en Bioquimica Clinica, LARESBIC) of the Argentine Biochemistry Foundation (Fundación Bioquímica Argentina), and the corresponding certificate was obtained from the Cholesterol Reference Method Laboratory Network (CDC, Atlanta, USA).
Cholesterol levels were defined as high $(\geq 200 \mathrm{mg} / \mathrm{dL})$, desirable $(<170 \mathrm{mg} / \mathrm{dL})$, and moderately high (170-199 mg/dL) ${ }^{14}$

\section{Hereditary and sociocultural outcome measures}

Family medical history (FMH): FMH was assessed using a survey designed by the authors in compliance with the SAP guidelines (Annex 1). It was dichotomized into positive $\mathrm{FMH}$ or unknown/negative FMH. Positive FMH was defined as any grandparent or parent having any of the vascular diseases described in the survey or both parents having hypercholesterolemia.

Socioeconomic level (SEL): SEL was assessed using the instrument designed by the Child Nutrition Study Center (Centro de Estudios Sobre Nutrición Infantil). ${ }^{15}$ It was also regarded as a dichotomous outcome measure (high/middle SEL or low SEL).

Nutritional status (NS): Weight and height were measured following the SAP guidelines for epidemiological studies. ${ }^{16}$ Body mass index was estimated, and NS was classified as per the International Obesity Task Force tables. ${ }^{17} \mathrm{NS}$ was dichotomized into NS obesity or NS overweight/ normal weight.

Diet (D) and physical activity (PA): Fat and cholesterol intake and PA level were assessed using surveys designed by specialists in the field (Annexes 2 and 3). Surveys were self-administered under the supervision and advice of the teachers of students participating in the study, who were trained in advance by the authors. Diet was semiquantified in grams of fat and cholesterol, divided into tertiles, and classified into upper, middle and lower tertile. Diet was dichotomized into D-upper or D-middle/lower. PA was semi-quantified into METs, divided into tertiles, and dichotomized into PA sedentary or PA moderately sedentary/active.

Parental cholesterol level: This specific information was obtained from the parents' answers to the FMH survey. This was considered a categorical outcome measure: both parents with hypercholesterolemia and both parents with normal cholesterol level. Children who had only one parent with hypercholesterolemia were excluded.

Note: Given that there are no criteria established for the dichotomization of cholesterol level and hereditary and sociocultural outcome measures, statistical tests were done using every possible combination, and this classification was adopted based on those that actually evidenced an association. 


\section{Statistical analysis}

The cholesterol level outcome measure was considered numerical to estimate central tendency and dispersion, and categorical to establish prevalence values as per cut-off points agreed upon by the American Academy of Pediatrics. ${ }^{14,18}$

Crude associations between each hereditary and sociocultural outcome measure and the cholesterol level response outcome measure were studied as categorical, dichotomous outcomes, and contingency tables were used to measure the power of the association using odds ratios, and the statistical significance was analyzed using Fisher's exact test.

The associations and relative power among independent outcome measures were studied using a logistic linear regression, estimating the odds ratio for each outcome measure as adjusted by the rest.

The association between parents who indicated to have hypercholesterolemia in the FMH survey and those who indicated to have normal cholesterol levels, and the cholesterol level response outcome measure in children was examined.

Tests were done to establish diagnosis, sensitivity, specificity, positive and negative predictive values, and positive and negative likelihood ratios using the outcome measures that showed an association with hypercholesterolemia.

For the statistical analysis, the InfoStat software, version 2012 (Grupo InfoStat, FCA, Universidad Nacional de Córdoba, Argentina) was used.

\section{Ethical considerations}

The methodological design applied in our research and the informed consent were assessed and approved by the Institutional Ethics and Health Research Committee of Polo Hospitalario (March 30 $0^{\text {th }}, 2009$ ) of the city of Córdoba. Data confidentiality was maintained.

Results were delivered to parents in a sealed envelope and a recommendation was made to have their local hospital or family physician look at them.

\section{RESULTS}

Out of the 503 students in the study population, 20 were excluded because they were older than 12 years of age or had a concomitant disease, 16 did not sign the informed consent, and 85 failed to complete all survey data or missed their blood draw appointment. The final number of assessed students was 382 , which accounts for $79 \%$ of the eligible group (95\% confidence interval [CI]: 75\%-82\%).

Participants' median age was 9.08 years old, ranging from 6.05 to 11.99 years old; $46.3 \%$ were girls. The average cholesterol level and standard deviation were $168 \pm 28 \mathrm{mg} / \mathrm{dL}$. The cholesterol level was higher than desirable in $45.6 \%$ of the population $(13.4 \%$, high and $32.2 \%$, moderately high).

Table 1 shows the distribution of cases by hereditary and sociocultural outcome measures.

The results of the bivariate analysis of hereditary and sociocultural outcome measures and the TC response outcome measure are

TABLE 1. Prevalence by category of hereditary and sociocultural outcome measures $(n=382)$

\begin{tabular}{llcc}
\hline Outcome measure & Classification & n & \% \\
\hline Family medical history & Positive & 189 & 49.5 \\
& Unknown & 97 & 25.4 \\
Socioeconomic level & Negative & 96 & 25.1 \\
& High & 106 & 27.7 \\
Nutritional status & Middle & 198 & 51.8 \\
& Low & 78 & 20.4 \\
Physical activity & Obesity & 40.5 & 14.7 \\
& Overweight & 56 & 74.9 \\
Diet (fat/cholesterol intake) & Normal weight & 286 & 22.8 \\
& Sedentary & 87 & 55.2 \\
& Moderately sedentary & 211 & 22.0 \\
\hline
\end{tabular}


shown in Table 2.

An association was found between a positive FMH and hypercholesterolemia, OR 2.10, 95\% CI: $1.32-3.34$, and $p=0.017$. A high/middle SEL showed the same OR (2.10), a 95\% CI of 1.32-3.36 and a $p$ value of 0.096 . NS obesity showed an OR of 2.05, a 95\% CI of 0.90-4.66, and a $p$ value of 0.076 .

No association was observed between hypercholesterolemia and either D upper $(p=0.54)$ or PA sedentary $(p=0.39)$.

Hypercholesterolemia in both parents showed an OR of 9.59, a 95\% CI of 1.29-57.09 and a $p$ value of 0.011 in relation to hypercholesterolemia in their child (Table 3).

The multiple logistic regression analysis indicated in Table 4 shows agreement with the findings of the bivariate analysis.

Table 5 shows the results of the diagnostic tests.

\section{DISCUSSION}

Between 1997 and 2003, our team conducted two cholesterol screenings in the student population. In 1997, 756 children and adolescents (5-17 years of age) were assessed, and $15.7 \%$ had a cholesterol level above $170 \mathrm{mg} / \mathrm{dL}$. Then in 2003, out of 1050 subjects in the same age group, the percentage of individuals with that cholesterol level had increased to $39.2 \% .{ }^{19}$ As a result, between 2003 and 2005, an education intervention aimed at the promotion of healthy habits was successfully implemented in all schools. ${ }^{20}$ The results of these experiences led to the formulation of this study's purpose and objectives.

The hypercholesterolemia prevalence observed in this study reveals an alarming epidemiological situation, even though it is consistent with what other studies conducted in different Argentinean regions have reported. ${ }^{21,22}$

TABLE 2. Results from the bivariate statistical analysis of categorical, dichotomous outcome measures $(n=382)$

\begin{tabular}{|c|c|c|c|c|c|c|c|c|c|c|}
\hline \multirow[t]{3}{*}{ Outcome measure } & \multirow[t]{3}{*}{ Classification } & \multicolumn{6}{|c|}{ Total cholesterol level } & \multirow{3}{*}{ OR $(*)$} & \multirow{3}{*}{$95 \% \mathrm{CI}$} & \multirow{3}{*}{$p(\#)$} \\
\hline & & \multicolumn{2}{|c|}{$\geq 200$} & \multicolumn{2}{|c|}{$<200$} & \multicolumn{2}{|c|}{ Total } & & & \\
\hline & & $\mathbf{n}$ & $\%$ & $\mathbf{n}$ & $\%$ & n & $\%$ & & & \\
\hline \multirow[t]{2}{*}{ Family medical history } & Positive & 33 & 64.7 & 156 & 47.1 & 189 & 49.5 & 2.10 & $(1.32-3.34)$ & 0.017 \\
\hline & Unknown/negative & 18 & 35.3 & 175 & 52.9 & 193 & 50.5 & & & \\
\hline \multirow[t]{2}{*}{ Socioeconomic level } & High/middle & 45 & 88.2 & 259 & 78.2 & 304 & 79.6 & 2.10 & $(1.32-3.36)$ & 0.096 \\
\hline & Low & 6 & 11.8 & 72 & 21.8 & 78 & 20.4 & & & \\
\hline \multirow[t]{2}{*}{ Nutritional status } & Obesity & 9 & 17.6 & 31 & 9.4 & 40 & 10.5 & 2.05 & $(0.90-4.66)$ & 0.076 \\
\hline & $\begin{array}{l}\text { Overweight/ } \\
\text { normal weight }\end{array}$ & 42 & 82.4 & 300 & 90.6 & 342 & 89.5 & & & \\
\hline \multirow[t]{2}{*}{ Physical activity } & Sedentary & 14 & 27.5 & 73 & 22.1 & 87 & 22.8 & 1.32 & $(0.73-2.38)$ & 0.442 \\
\hline & $\begin{array}{l}\text { Moderately sedentary / } \\
\text { active }\end{array}$ & 37 & 72.5 & 258 & 77.9 & 295 & 77.2 & & & \\
\hline Diet & Upper & 15 & 29.4 & 87 & 26.3 & 102 & 26.7 & 1.18 & $(0.68-2.04)$ & 0.618 \\
\hline (fat/cholesterol intake) & Middle/lower & 36 & 70.6 & 244 & 73.7 & 280 & 73.3 & & & \\
\hline
\end{tabular}

OR: odds ratio; CI: confidence interval.

(*) Mantel-Haenszel odds ratio; (\#) Cochran-Mantel-Haenszel test.

TABLE 3. Cholesterol level correlation between children with cholesterol $\geq 200 \mathrm{mg} / \mathrm{dL}$ or $<200 \mathrm{mg} / \mathrm{dL}$ and both parents with hypercholesterolemia ( $\geq 240 \mathrm{mg} / \mathrm{dL}$ ) or normal cholesterol level $(<240 \mathrm{mg} / \mathrm{dL})$

\begin{tabular}{|c|c|c|c|c|c|c|c|c|c|c|}
\hline \multirow{3}{*}{ Outcome measure } & \multirow{3}{*}{ Classification } & \multicolumn{6}{|c|}{ Children's cholesterol level $(n=32)$} & \multirow{3}{*}{ OR } & \multirow{3}{*}{$95 \% \mathrm{CI}$} & \multirow{3}{*}{$p$} \\
\hline & & \multicolumn{2}{|c|}{$\geq 200$} & \multicolumn{2}{|c|}{$<200$} & \multicolumn{2}{|c|}{ Total } & & & \\
\hline & & $\mathbf{n}$ & $\%$ & $\mathbf{n}$ & $\%$ & $\mathbf{n}$ & $\%$ & & & \\
\hline \multirow[t]{3}{*}{ Parents' cholesterol level } & Both $\geq 240$ & 8 & 23.5 & 6 & 3.9 & 14 & 43.8 & \multirow{3}{*}{9.59} & \multirow{3}{*}{$(1.29-57.09)$} & \multirow{3}{*}{0.011} \\
\hline & & & & & & & & & & \\
\hline & Both normal & 3 & 8.8 & 15 & 9.8 & 18 & 56.3 & & & \\
\hline
\end{tabular}

OR: odds ratio; CI: confidence interval. 
The level of concern grows if we observe that a fourth of children $(25.2 \%)$ are overweight or obese, their fat and cholesterol intake is high, and $78 \%$ are sedentary or moderately sedentary.

PA and diet surveys have not provided the expected results in terms of prediction or association with hypercholesterolemia. It may be argued that the different levels of susceptibility in each individual resulted in dissimilar answers to external stimuli. It was decided that surveys should not be completed together with or by parents themselves for fear that the information provided by adults would be false; however, having children complete the surveys themselves, even if guided by their teachers, may pose doubts regarding the recall of their actual weekly intake given that these children, especially the younger ones, may not be capable of adequately measuring food intake or motor activities.

The $p$ value obtained for NS obesity and SEL high/middle was not lower than the significance level specified in the methodology; however, in order to investigate the association structure and considering that the sample accounts for practically the entire population (79\%), in this study we decided to consider as positive the association between hypercholesterolemia and NS obesity and SEL high/middle, given that the OR was $>2$.
The association observed between hypercholesterolemia and SEL is consistent with the findings of other study conducted in Río Cuarto, Córdoba, by Doctor Lubetkin in the child and adolescent population. ${ }^{8}$

Obesity was found in $10.5 \%$. There is a popular tendency to relate obese subjects with hypercholesterolemia.

Although a previous study showed that this association had varying results and differences among countries in terms of culture, ethnicity and gender, a relatively strong association was observed. ${ }^{9}$ The sensitivity and positive predictive value of NS were low, but its specificity and negative predictive value were high, and this may indicate a relationship between nonobese children and those who do not have hypercholesterolemia.

A limitation of this study may be that it included overweight and normal weight children in the same category.

Although the specificity of a positive $\mathrm{FMH}$ was low, as reported in other studies, ${ }^{23}$ its sensitivity was adequate, so it may be considered a predictor of hypercholesterolemia in this type of population, as suggested by pediatric societies. ${ }^{11,14}$

The 2008 American Academy of Pediatrics' guidelines ${ }^{14}$ describe certain level of concern regarding the epidemic of childhood obesity

TABLE 4. Multivariate logistic regression analysis of hereditary and sociocultural outcome measures in relation to cholesterol level $(n=382)$

\begin{tabular}{lcccc} 
Regression outcome measures & \multicolumn{3}{c}{ Dependent outcome measure: cholesterol level } \\
& OR & $\mathbf{9 5 \%}$ CI & $\chi^{\mathbf{2}}$ & p \\
\hline Positive family medical history & 2.20 & $(1.18-4.13)$ & 6.07 & 0.014 \\
High/middle socioeconomic level & 2.12 & $(0.85-5.25)$ & 2.60 & 0.107 \\
Nutritional status: obesity & 2.15 & $(0.94-4.93)$ & 3.25 & 0.071 \\
Physical activity: sedentary & 1.60 & $(0.80-3.21)$ & 1.79 & 0.180 \\
Diet (fat/cholesterol intake): upper tertile & 1.34 & $(0.69-2.62)$ & 0.75 & 0.388 \\
\hline
\end{tabular}

OR: odds ratio; CI: confidence interval.

TABLE 5. Predictive values of family medical history, socioeconomic level, nutritional status, and parental cholesterol level

\begin{tabular}{|c|c|c|c|c|c|c|}
\hline & Sensitivity & Specificity & PPV & NPV & LR+ & LR- \\
\hline Positive family medical history & $75 \%$ & $35 \%$ & $17 \%$ & $89 \%$ & 1.16 & 0.71 \\
\hline High/middle socioeconomic level & $88 \%$ & $22 \%$ & $15 \%$ & $92 \%$ & 1.13 & 0.54 \\
\hline Nutritional status: obesity & $18 \%$ & $91 \%$ & $23 \%$ & $88 \%$ & 1.88 & 0.91 \\
\hline Both parents with hypercholesterolemia & $73 \%$ & $71 \%$ & $57 \%$ & $83 \%$ & 2.55 & 0.38 \\
\hline
\end{tabular}

PPV and NPV: positive and negative predictive value; LR+ and LR-: positive and negative likelihood ratio. 
and propose introducing the screening for every overweight or obese children, regardless of their $\mathrm{FMH}$.

If we had applied these criteria to our study, considering children with a positive or unknown FMH together with overweight or obese children with a negative FMH, we should have assessed 316 subjects ( $82.7 \%$ of the total 382 ). Paradoxically, out of the 66 children we would have left out of the assessment, 34 (51\%) had a cholesterol level above $170 \mathrm{mg} / \mathrm{dL}$; therefore, using these criteria, the difference between the guided screening and the universal screening would be irrelevant.

The latest recommendations made by expert meetings in the USA, established in 2011, introduce additional criteria suggesting the inclusion of children with other risk factors, such as hypertension, smoking, etc., and propose a universal screening for every child between 9 and 11 years of age and between 17 and 21 years of age..$^{18}$ The SAP, in its latest consensus meeting, suggested the universal screening for children aged 6 to 11 years old, which is precisely what we did in this study. ${ }^{24}$

An analysis done by Kusters et al. ${ }^{23}$ regarding several European countries indicates that the screening based on FMH lacks accuracy and there is a high proportion of children who are left undiagnosed. The Netherlands, Norway, and the United Kingdom have a familial hypercholesterolemia detection program based on a deoxyribonucleic acid (DNA) test done in family groups and an adequate technique, but it is costly. Slovenia performs a cholesterol screening in every pre-school child at 5 years of age. Italy proposes a screening based on $\mathrm{FMH}$ and ordered by pediatricians. Kusters et al. conclude by proposing that a universal screening in every child, from 1 to 9 years of age, is the most effective strategy, but this still has to be demonstrated in clinical practice. It is estimated that such massive strategy renders its implementation difficult.

A very strong correlation was observed in the analysis of hypercholesterolemia and normal cholesterol level in both parents whose children had the same condition, and diagnostic test results proved to be highly valuable. Failure to include in the analysis children who had only one parent with hypercholesterolemia may have been a limitation. Future studies are required to further analyze the relationship between the presence of hypercholesterolemia in one parent and their child's cholesterol level.
A review published by Catherine $\mathrm{McNeal}^{25}$ states that dyslipemia in children and adults is the result of inherited or acquired conditions. The genetic bases for hypercholesterolemia are well defined, so transmission of this phenotype from parents to children is a fact and responds to the laws of inheritance. ${ }^{26,27}$

In addition, there are sociocultural characteristics, such as eating and physical activity habits, which tend to be common to the family and may have a positive or negative impact on hypercholesterolemia. ${ }^{28}$

The results of this study on the cholesterol level in parents and children, and the empirical, observational evidence supported by the studies conducted by our team for the past 18 years, indicate that there are plenty of cases of children with hypercholesterolemia whose parents also have it.

We recommend focusing studies on the relationship between the cholesterol level of parents and children to find tools that help to improve screening criteria.

\section{CONCLUSION}

No association was established between hypercholesterolemia and a sedentary lifestyle, or between hypercholesterolemia and a fat- and cholesterol-rich diet.

A positive FMH, a high/middle SEL, and obesity were associated with hypercholesterolemia.

An association was also found between the cholesterol level of both parents and that of their child and a high prediction value in diagnostic tests.

\section{Acknowledgments}

To Laura Moreno, M.D., tutor of Robledo's dissertation, one of the authors. This article is part of his dissertation.

To schools, teachers, the healthcare providers team, and volunteers who helped with the field work.

To the scientific advisors and institutions who support the Inter-Agency Program for Health Prevention and Education (Programa Interinstitucional de Prevención y Educación en Salud, PIPES).

To Fernando Torres for his wise, generous advice.

To the School of Pharmacists of the Province of Córdoba. 


\section{REFERENCES}

1. Thompson RC, Allam AH, Lombardi GP, Wann LS, et al. Atherosclerosis across 4000 years of human history: the Horus study of four ancient populations. Lancet 2013; 381(9873):1211-22.

2. Organización Mundial de la Salud. Informe sobre la Salud en el Mundo 2002. Reducir los riesgos y promover una vida sana. Ginebra: Organización Mundial de la Salud; 2002.

3. Enos WF, Holmes RH, Beyer J. Coronary disease among United States soldiers killed in action in Korea; preliminary report. J Am Med Assoc 1953;152(12):1090-3.

4. Strong JP, Malcom GT, McMahan CA, Tracy RE, et al. Prevalence and extent of atherosclerosis in adolescents and young adults: implications for prevention from the Pathobiological Determinants of Atherosclerosis in Youth Study. JAMA 1999;281(8):727-35.

5. Couch SC, Cross AT, Kida K, Ros E, et al. Rapid westernization of children's blood cholesterol in 3 countries: evidence for nutrient-gene interactions? Am J Clin Nutr 2000;72(5 Suppl):1266S-74S.

6. KobayashiS. Trends in national nutritional survey of Japan. Nutr Health 1992;8(2-3):91-6.

7. PaternoCA. Factores de riesgo coronario en la adolescencia. Estudio FRICELA. Rev Esp Cardiol 2003;56(5):452-8.

8. Granero M, Lubetkin A, Falappa JL. Valoración del colesterol y otros factores de riesgo de ateroesclerosis en niños y adolescentes: un desafío en medicina. Río Cuarto: Fundación de la Universidad de Río Cuarto; 1998.Págs.2633.

9. Bingham MO, Harrell JS, Takada $\mathrm{H}$, Washino $\mathrm{K}$, et al. Obesity and cholesterol in Japanese, French, and U.S. children. J Pediatr Nurs 2009;24(4):314-22.

10. Berenson GS, Srinivasan SR. Consideration of serum cholesterol in risk factor profiling for all young individuals. Nutr Metab Cardiovasc Dis 2001;11(Suppl 5):1-9.

11. Grupo de Hipercolesterolemia. Consenso sobre factores de riesgo de enfermedad cardiovascular en pediatría. Hipercolesterolemia. Arch Argent Pediatr 2005;103(4):35866.

12. O’LoughlinJO,LauzonB,ParadisG,HanleyJ,etal.Usefulness of the American Academy of Pediatrics recommendations for identifying youths with hypercholesterolemia. Pediatrics 2004;113(6):1723-7.

13. Bentz MH, Magnette J.Hypocholestérolémie au cours de la phase aiguëdela réaction inflammatoired origineinfectieuse. Â propos de 120 cas. Rev Med Interne 1998;19(3):168-72.
14. Daniels SR, Greer FR. Lipid screening and cardiovascular health in childhood. Pediatrics 2008;122(1):198-208.

15. CESNI-CLACYD. Encuesta de salud, nutrición y desarrollo. Mamás y niños del 2000. Córdoba: Municipalidad de Córdoba; 2000

16. Comité Nacional deCrecimientoy Desarrollo. Guías parala evaluación del crecimiento. 2a ed. Buenos Aires: Sociedad Argentina de Pediatría; 2001.

17. Cole TJ, Flegal KM, Nicholls D, Jackson AA. Body mass index cut offs to define thinness in children and adolescents: international survey. BMJ 2007;335(7612):194.

18. Expert panel on integrated guidelines for cardiovascular health and risk reduction in children and adolescents: summary report. Pediatrics 2011;128(Suppl 5):S213-56.

19. Lubetkin AM, Robledo JA, Siccardi LJ, Rodriguez MI. Prevalencia de hipercolesterolemia en la población estudiantil de una localidad de la provincia de Córdoba. Arch Argent Pediatr 2005;103(4):298-304.

20. Robledo JA, Siccardi LJ, Cosio F, Rodríguez MI, et al. Disminución dehipercolesterolemia infantojuvenil tras dos años de intervención. Arch Argent Pediatr 2009;107(6):48895.

21. Pedrozo WR, Bonneau G, Castillo Rascón MS, Juárez M, et al. Valores de referencia y prevalencia de las alteraciones del perfil lipídico en adolescentes. Arch Argent Pediatr 2010;108(2):107-15.

22. Rosillo I, Pituelli N, Corbera M, Lioi S, et al. Perfil lipídico en niños y adolescentes de una población escolar. Arch Argent Pediatr 2005;103(4):293-7.

23. Kusters DM, de Beaufort C, Widhalm K, Guardamagna $\mathrm{O}$, et al. Paediatric screening for hypercholesterolaemia in Europe. Arch Dis Child 2012;97(3):272-6.

24. Sociedad Argentina de Pediatría. Comité de Nutrición. Consenso sobre manejo de las dislipidemias en pediatría. Arch Argent Pediatr 2015;113(2):177-86.

25. McNealCJ, Underland L, Wilson DP, Blackett PR. Pediatric lipid screening. Clin Lipidol 2013;8(4):425-36.

26. Yuan G, Wang J, Hegele RA. Heterozygous familial hypercholesterolemia: an underrecognized cause of early cardiovascular disease. CMAJ 2006;174(8):1124-9.

27. Soutar AK, Naoumova RP. Mechanisms of disease: genetic causes of familial hypercholesterolemia. Nat Clin Pract Cardiovasc Med 2007;4(4):214-25.

28. GrundySM.Multifactorialetiology of hypercholesterolemia. Implications for prevention of coronary heart disease. Arterioscler Thromb 1991;11(6):1619-35. 
Annex 1

Survey on family medical history

\section{Inter-Agency Program for Health Prevention and Education}

"Dr. Alberto Lubetkin"

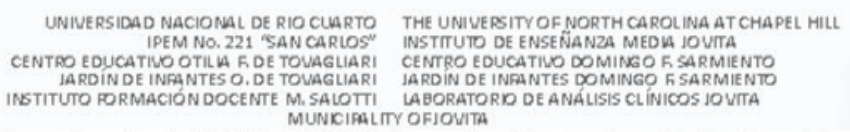

MINTCATI OFJOVITA

General Paz 75 - 6127 Jovita - Córdoba - Argentina / tel: $03384-498070$ / e-mall address: plpes.Jovita @ogmall.com

Last and first names:

Date of birth: ID number: School: Class: Section:

\section{$\underline{\text { Pipes - Family medical history }}$}

\section{Personal data}

Weight at birth:

Has the child been diagnosed with any of the following conditions?

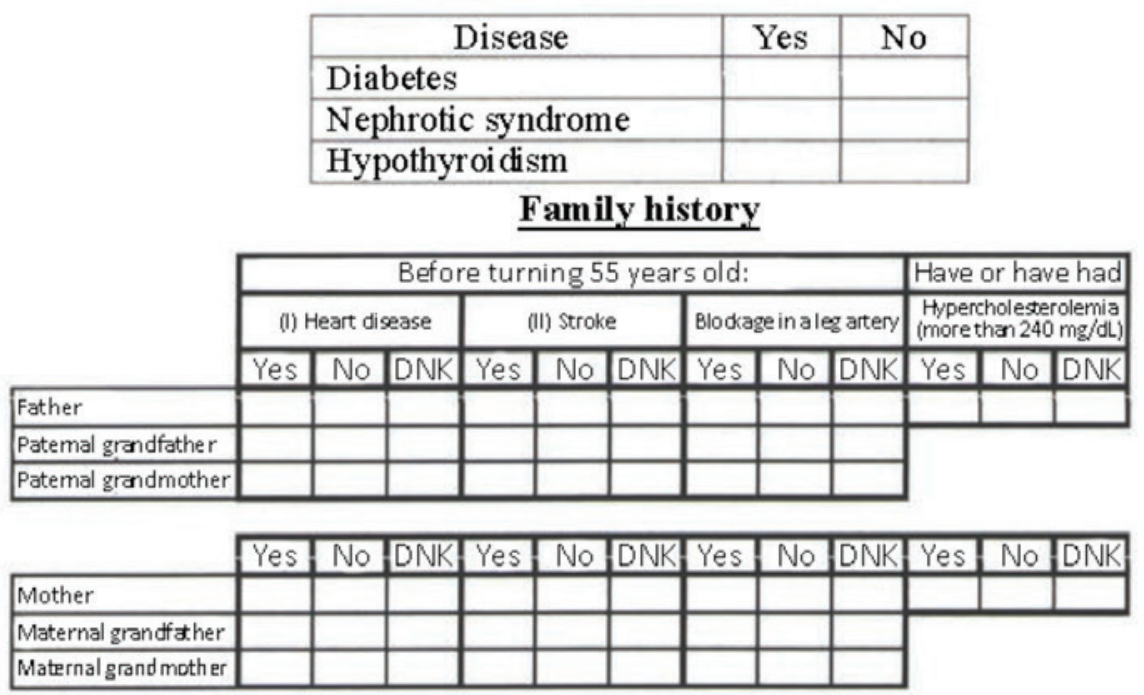

I) Heart disease

It includes: Sudden death, cardiac failure, myocardial infarction, coronary bypass, angioplasty, and diagnosed coronary artery arteriosclerosis

II) Stroke

It includes: Cerebral venous thrombosis, hemiplegia, cerebrovascular accident

Survey taker: Date:

Survey design: Jorge Robledo, M.D., and Leonardo Siccardi, M.D. 
Annex 2

Survey on diet

\section{Inter-Agency Program for Health Prevention and Education}

"Dr. Alberto Lubetkin"

UNIVE RSIDAO NACWONAL OE RIOCUARTO THE UNIVERSTY OE NORTH CAROUNA ATCHAPEL HIL

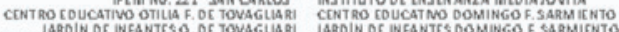

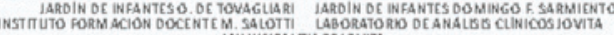

General Paz 75 - 6127 Jovita - Córdoba - Argentina / tel: 03384 - 498070/ e-mail address: pipes.jovita@gmail.com

Last and first names:

School:
Date of birth:

Class:
ID number: Section:

\section{EATING HABITS}

ACTIVITY: Paint the empty b oxes in the upper right corner of each picture.

1. Red means you eat it every day

2. Blue means you eat it three or four times a week.

3. Yellow means you eat it once or twice a week.

4. Leave unpainted if you never eat this.
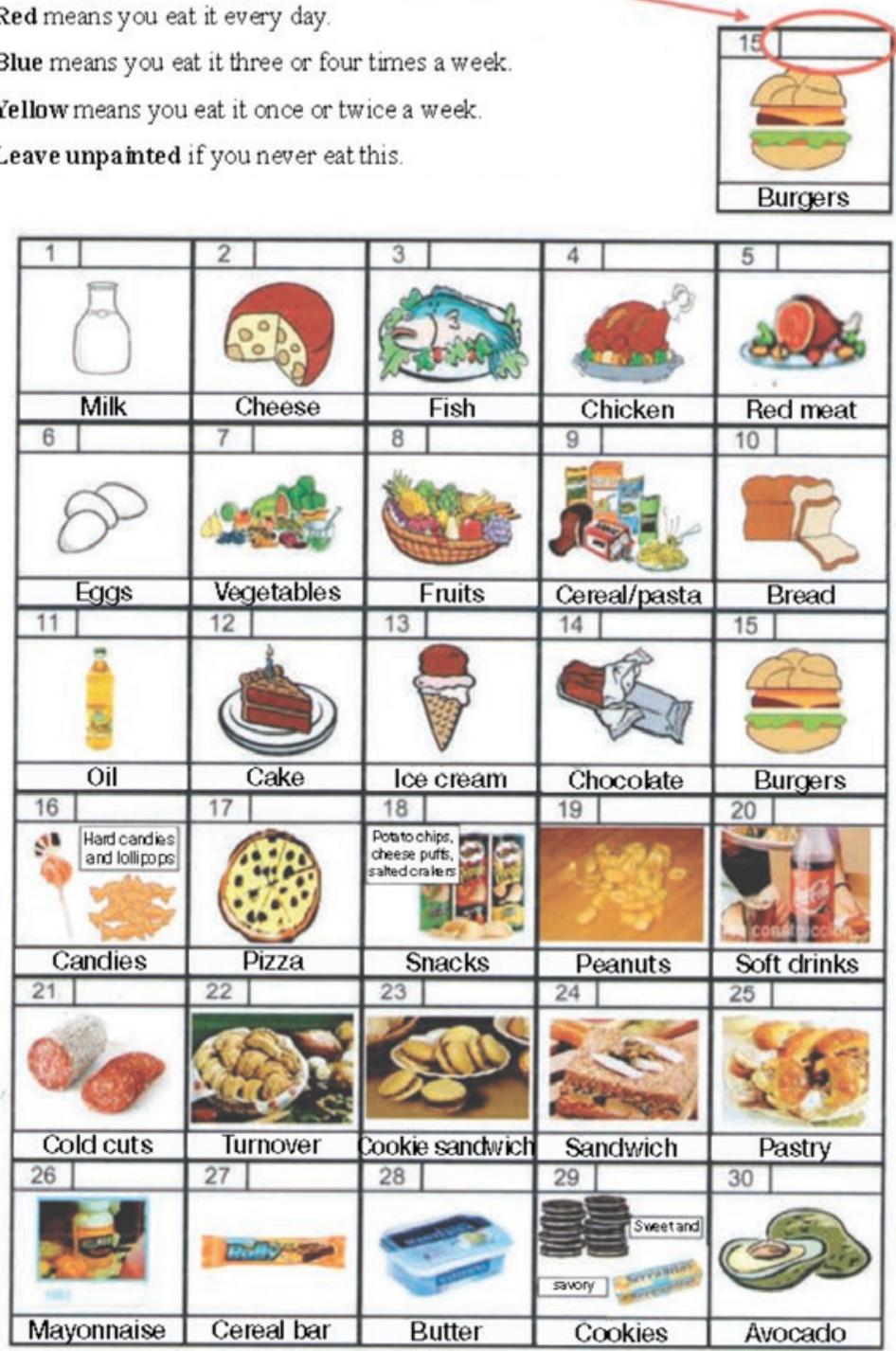

Survey taker:

Date: 
Annex 3

Survey on physical activity

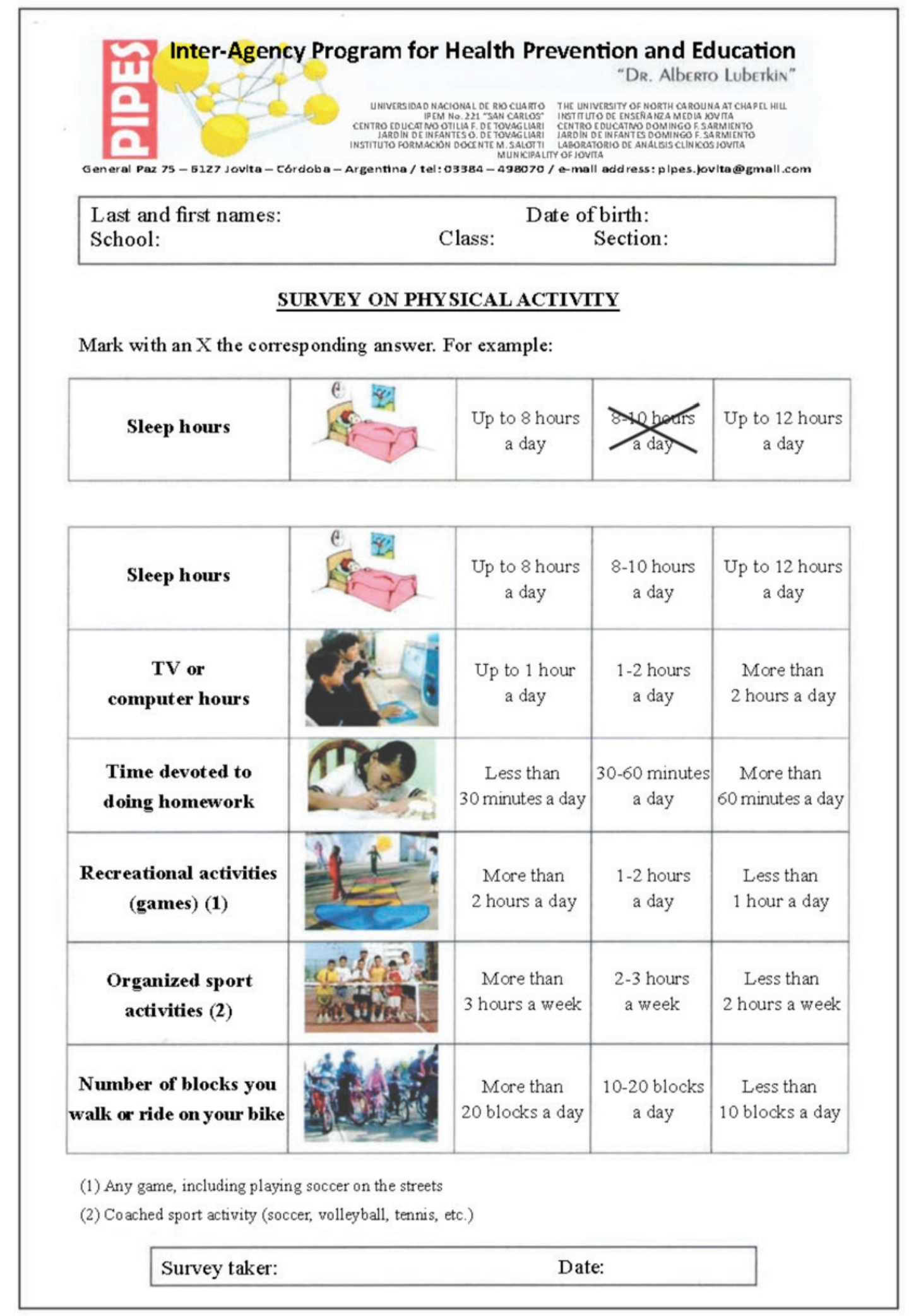

